\title{
The Analysis of the Competitiveness of International Service Outsourcing in Western China Under the "the Belt and Road Initiatives"
}

\author{
Wang Zongguang ${ }^{1, a}$, Li Qianjin ${ }^{2, b^{*}}$ \\ ${ }^{1}$ Professor, School of economics and management, Lanzhou University of Technology, Lanzhou, Gansu Province, China \\ ${ }^{2}$ Graduate Student, School of economics and management, Lanzhou University of Technology, Lanzhou, Gansu Province, \\ China \\ 1966544907@qq.com \\ b*455962433@qq.com
}

\begin{abstract}
This paper expatiates the status quo of China's western region to undertake service outsourcing, based on the core competence theory, through factor analysis and clustering analysis in western central cities such as Lanzhou, Kunming as sample. Analyzing the cities service outsourcing competitiveness, classification and evaluation, we can draw a conclusion: Chongqing, Chengdu are the core leading representative cities. Xian is a representative city of development model. Hohhot, Lanzhou, Kunming, Urumqi, are the representative cities of the late boom. Guiyang, Nanning, Xining, Yinchuan, Lhasa are the representative cities of progressive potential. And combining the analysis results, respectively, we can put forward the corresponding measures and suggestions. Under the background of "One Belt and One Road" policy, it provides referential significance for the service outsourcing industry to strengthen its own characteristic guidance and take the road of differentiated development and dislocation competition.
\end{abstract}

Keywords: service outsourcing, international service, competitiveness level

“一带一路”倡议下中国西部地区国际服务外包竞争力 水平探析

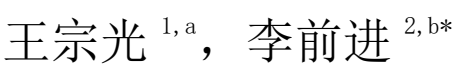

${ }^{1}$ 兰州理工大学经济管理学院教授, 兰州, 甘肃, 中国

${ }^{2}$ 兰州理工大学经济管理学院研究生, 兰州, 甘肃, 中国

1966544907@qq.com

b*455962433@qq.com

\section{摘要}

本文通过阐述我国西部地区承接服务外包的现状特点, 以核心竞争力理论为依托，通过因子分析与聚 类分析以兰州、昆明等西部核心城市为样本，对各个城市服务外包竞争力进行分析、归类与评价，得 出结论: 重庆、成都为核心引领型代表城市, 西安为发展示范型代表城市, 呼和浩特、兰州、昆明、乌 鲁木齐为后起勃发型代表城市，贵阳、南宁、银川、拉萨、西宁为进步潜力型代表城市，并结合分析 结果分别提出相应的措施与建议。为服务外包行业在 “一带一路” 政策背景下，加强对自身特色产业 指导, 走差异化发展、错位竞争的发展道路提供了借鉴意义。

关键词: 服务外包; 国际服务; 竞争力水平

1. 前言

在全球经济数字化和服务经济一体化的背景下, 国
际服务外包为推动全球经济发展和推动产业结构调整 做出了卓越的贡献（徐敏芝，2019） ${ }^{[1]}$ ，同时服务外包 行业在国际上也不断的受到企业的青睐。我国西部地区 应当根据当地的资源禀赋条件, 积极优化服务外包产业 结构。在经济发展新形势下, “一带一路” 战略的提出 


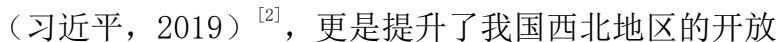
型经济水平。因此随着 “一带一路” 政策红利不断显现, 西北地区更应该抓住产业转型机遇, 转变经济合作模式, 提升区域经济合作水平与质量, 更好的激发经济增长活 力。

\section{2. 我国西部地区承接国际服务外包的现状与 特点}

\section{1. 交易规模扩大}

根据《中国外包品牌发展报告 2019》显示，我国在 连续九年的时间里成为第二大全球服务外包承接国。 2018 年我国企业承接服务外包执行金额更是达到了 9597.4 亿元人民币，交易规模也在逐年增加。

\section{2. 业务范围拓宽}

随着信息技术的迅速发展和科学技术的不断更新, 服务外包行业越来越依赖对知识技术水平的需求。众多 公司还将风险控制管理、企业科技研发等技术含量水平 高的业务也开始外包出去。

\section{3. “一带一路” 凸显政策红利}

2019 年，中国承接 “一带一路” 沿线国家离岸服务 外包执行额 1249.5 亿元, 同比增长 $12.4 \%$ 。随着互联互 通, 中欧班列和 “互联网+” 工程的推进, 西部地区较 之于东部地区，也更有优势获得潜在市场与目标客户。

\section{4. 外包结构不断优化}

截止 2019 年上半年底, 我国服务外包产业已经累 计吸纳就业人员超过了 1091 万人, 大学以上学历人数 也在不断的增加, 就业结构不断地优化; 云计算、大数 据等服务外包新模式也不断的与数字经济进行融合与 创新。

\section{3. “一带一路” 倡议下中国西部地区国际服务 外包竞争力评价}

\section{1. 西部地区服务外包竞争力评价体系理论 依据}

核心竞争力理论指出 (Prahalad \& Hame1, 1989), 核心竞争力一般是国家或企业相较于竞争对手而言所 具备的竞争优势与核心能力差异，是一个国家（企业, 个人或者参与竞争的个体) 能够长期获得竞争优势的能 力, 是一个国家或者企业、个人在发展中的一组非常关 键和具有核心力的因素, 它的组成部分通常是能力与资 源。因此，我们对于国家或者行业、个人核心竞争力的 研究, 就需要更加注重对它的能力与资源进行分析。

\section{2. 构建服务外包竞争力评价体系}

首先，对于评价体系方法的选择上，本文通过利用 因子分析法和聚类分析法来构建我国西部地区服务外 包竞争力的评价模型。综合评价函数通过以各个主因子 旋转后的方差贡献率得到, 并且通过聚类分析对各个地 区进行分析。通过这两个方法对我国西部地区服务外包 竞争力进行进一步的评价。

其次，通过对服务外包行业的特点以及核心竞争力 理论的应用, 并结合中国服务外包产业发展报告 (2018) 发布的中国服务外包示范城市的发展与竞争力评价框 架，选取了产业发展情况、基础设施建设状况、人力资 源、要素成本和政策因素方面的 10 个指标。同时以重 庆、成都、西安、南宁、乌鲁木齐 5 个国家级示范城市 以及兰州、昆明、拉萨、贵州、西宁、银川、呼和浩特 7 个发展潜力较大的中心城市的各项指标 (为确保数据 的准确性与可靠性, 12 个城市数据来源于《中国城市统 计年鉴 2018》、国家统计局网站、各大城市 2018 年统计 年鉴）构建我国西部地区服务外包竞争能力的评价体系。

\section{3. 实证分析}

\section{3. 1. KMO 与 Bartlett 球形检验}

$\mathrm{KMO}=$ 所有变量间相关系数平方和/（所有变量间相 关系数平方和 + 所有变量间偏相关系数平方和 ), 一般情 况下, KMO 值在 0.6 以上就可以做因子分析，当它的值 接近于 1 的时候，因子分析的合适度越高。本文采用 SPSS 23 软件对 12 个城市所搜集到的指标数据进行因 子分析, 对变量数据进行 KMO 与 Bartlett 球形检验, 结果如表 1 , KM0 的值为 0.606 , Bartlett 球形检验在 99. 9\%水平下显著, 结果表明, 适合进一步进行因子分析。

表 $1 \mathrm{KMO}$ 与 Bartlett 检验 $(\mathrm{N}=10)$

\begin{tabular}{|c|c|}
\hline KM0 测量取样适当性 & 0.606 \\
\hline Bartlett 的球形检验卡方值 & 198.073 \\
\hline $\mathrm{df}$ & 45 \\
\hline 显著性 & 0.000 \\
\hline
\end{tabular}


本文按照因子提取中的主成分法默认特征值大于 1 的提取原则, 得到 2 个因子 F1 和 F2, 因子特征根均大

表 2 说明的变异数总计 $(\mathrm{N}=10)$

\begin{tabular}{|c|c|c|c|c|c|c|c|c|c|}
\hline & \multicolumn{3}{|c|}{ 起始特征值 } & \multicolumn{3}{c|}{ 倾取平方和载入 } & \multicolumn{3}{c|}{ 循环平方和载入 } \\
\hline 组件 & 总计 & 变异的\% & 累加\% & 总计 & 变异的\% & 累加\% & 总计 & 变异的\% & 累加\% \\
\hline 1 & 7.425 & 74.252 & 74.252 & 7.425 & 74.252 & 74.252 & 6.469 & 64.685 & 64.685 \\
\hline 2 & 1.077 & 10.771 & 85.023 & 1.077 & 10.771 & 85.023 & 2.034 & 20.338 & 85.023 \\
\hline 3 & 0.780 & 7.801 & 92.824 & & & & & & \\
\hline 4 & 0.512 & 5.118 & 97.942 & & & & & & \\
\hline 5 & 0.154 & 1.537 & 99.478 & & & & & & \\
\hline 6 & 0.030 & 0.295 & 99.774 & & & & & & \\
\hline 7 & 0.015 & 0.146 & 99.920 & & & & & & \\
\hline 8 & 0.007 & 0.068 & 99.988 & & & & & & \\
\hline 9 & 0.001 & 0,011 & 99.998 & & & & & & \\
\hline 10 & 0.000 & 0,002 & 100.000 & & & & & & \\
\hline
\end{tabular}

从表 3 中我们通过经载荷矩阵得到的旋转因子矩阵 可以看出, 主因子 F1 在普通高等学校在校生数量、普 通高等学校数、移动电话年末用户、进出口总额、专利 申请受理数、实际利用外资额、互联网宽带接入用户数、 外商投资企业总产值指标上占有较高载荷, 分别为 $0.927 、 0.925 、 0.916 、 0.913 、 0.911 、 0.879 、 0.856$ 和 0.781 。其中普通高等学校在校生数量、普通高等学校数 指标反映城市的人力资源实力; 移动电话年末用户、互 联网宽带接入用户数反映了城市信息技术发展潜力; 专 利申请受理数反映了城市知识产权政策发展能力; 进出 口总额、实际利用外资额、外商投资企业总产值则反映
城市的产业发展情况规模。因此可以将主因子 F1 定义 为外包行业发展竞争力。主因子 F2 在第三产业对生产 总值增长的贡献率、客运量占有较高载荷, 而第三产业 对生产总值增长的贡献率反映了外包企业整体的发展 水平, 而客运量反映基础设施下的要素成本量。因此主 因子 F2 可以解释为外包行业环境水平。同时, 我们可 以看出, 主因子 F1 解释了 $64.685 \%$ 的总体方差, 而主因 子 F2 解释了 $20.034 \%$ 的总体方差, 因此可以看出, 企业 发展竞争力为主要的评判因子, 对外包竞争能力的评判 过程中, 也显得格外的重要。

表 3 旋转组件矩阵 a $(\mathrm{N}=10)$

\begin{tabular}{|c|c|c|}
\hline \multirow{2}{*}{} & \multicolumn{2}{|c|}{ 组件 } \\
\cline { 2 - 3 } & 1 & 2 \\
\hline 普通高等学校在校生数量 & 0.927 & -0.028 \\
\hline 普通高等学校数 & 0.925 & 0.069 \\
\hline 移动电话年末用户 (万户) & 0.916 & 0.382 \\
\hline 进出口总额 (亿元) & 0.913 & 0.360 \\
\hline 专利申请受理数 & 0.911 & 0.221 \\
\hline 实际利用外资额(万美元) & 0.879 & 0.439 \\
\hline 互联网宽带接入用户数(万户) & 0.856 & 0.442 \\
\hline 外商投资企业总产值 (万元) & 0.781 & 0.511 \\
\hline 第三产业对生产总值增长的贡献率 & -0.012 & -0.904 \\
\hline 客运量 $($ 万人) (公路、水运、民航) & 0.369 & 0.486 \\
\hline
\end{tabular}

\section{3. 3. 中国西部地区服务外包竞争力样本数 据因子得分}

本文通过 SPSS 23.0 进行回归分析自动生成各主因
子得分, 然后根据权重=各主因子方差贡献率/总方差贡 献率计算公式, 得出权重系数, 最后与各主因子得分加 权求和, 得到西部地区主要城市的服务外包竞争力评估 模型:

$$
F=0.761 * F 1+0.239 * F 2
$$

其中, $F$ 为综合得分, F1 与 $F 2$ 分别为二个主因子。 
从 F1 外包行业发展竞争力来看, 西安、成都、重庆为 排名的前三名, 而银川、拉萨和西宁排名较后; 从 F2 外 包行业环境水平来看, 重庆、西宁、成都排名相对靠前,
而兰州、西安、乌鲁木齐相对靠后。根据综合得分来看, 重庆、成都与西安的服务外包竞争力较大, 而银川、西 宁、拉萨的服务外包竞争力相对较弱, 结果如表 4。

\section{表 4 西部地区服务外包竞争力排序 $(\mathrm{N}=10)$}

\begin{tabular}{|c|c|c|c|c|c|c|}
\hline 城市 & $F 1$ & $F 1$ 排名 & $F 2$ & $F 2$ 排名 & $F$ & $F$ 综合得分排名 \\
\hline 重庆 & 1.46877 & 3 & 1.58358 & 1 & 1.5 & 1 \\
\hline 成都 & 1.53237 & 2 & 0.79252 & 2 & 1.36 & 2 \\
\hline 西安 & 1.59023 & 1 & -1.07901 & 3 & 0.95 & 3 \\
\hline 昆明 & -0.02137 & 5 & -0.26682 & 8 & -0.08 & 4 \\
\hline 贵阳 & -0.47939 & 9 & 0.73416 & 4 & -0.19 & 5 \\
\hline 南宁 & -0.40633 & 8 & 0.20324 & 7 & -0.26 & 6 \\
\hline 兰州 & -0.14155 & 6 & -1.04653 & 10 & -0.36 & 7 \\
\hline 乌鲁木齐 & -0.01218 & 4 & -1.71286 & 11 & -0.42 & 8 \\
\hline 呼和浩特 & -0.32876 & 7 & -0.91541 & 9 & -0.47 & 9 \\
\hline 银川 & -0.95159 & 10 & 0.4978 & 5 & -0.61 & 10 \\
\hline 西宁 & -1.17428 & 12 & 0.92269 & 12 & -0.67 & 11 \\
\hline 拉萨 & -1.07591 & 11 & 0.28665 & 6 & -0.75 & 12 \\
\hline
\end{tabular}

\section{3. 4. 聚类分析}

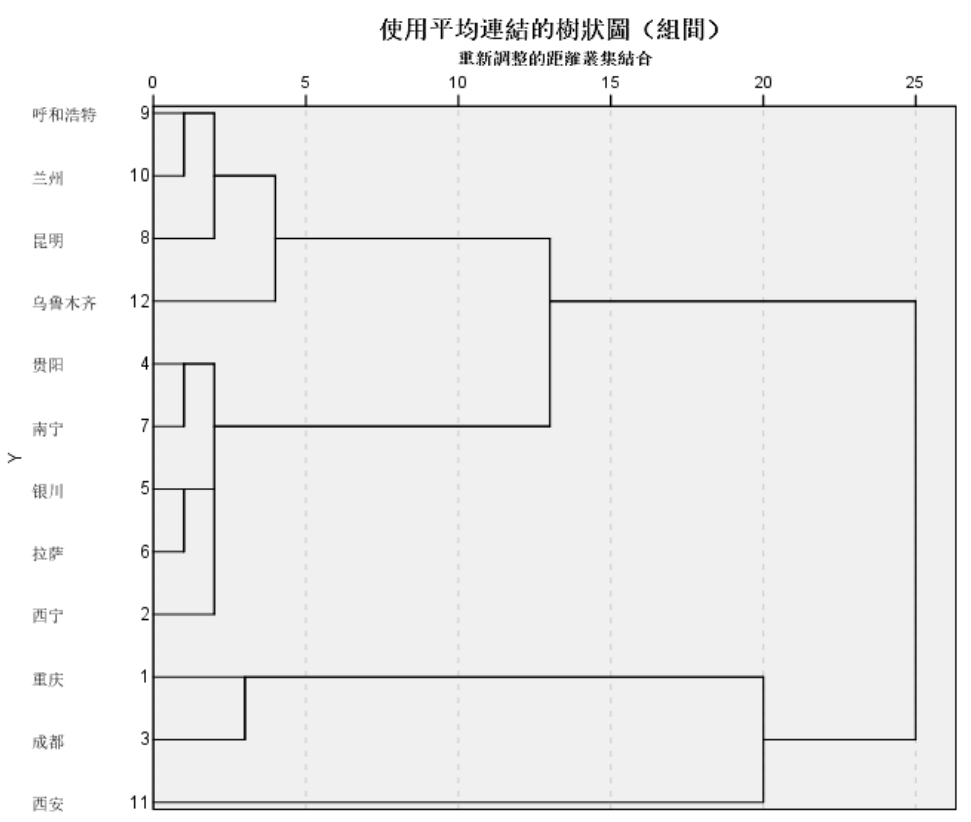

图 1 聚类分析图

为更好地分析西部地区服务外包竞争力的水平层 次, 进而能够明确西部地区服务外包竞争力排名, 我们 采用聚类分析, 结果如图 1 所示。结合竞争力水平进行 梯度划分, 得出聚类图并将它们分为四类: 分别为核心 引领型、发展示范型、后期勃发型、进步潜力型。

(1) 核心引领型

重庆、成都。2019 年重庆市建设了国家数字经济 创新发展试验区，而四川的电子信息产业聚集效应明显。 重庆和成都将服务外包与物联网、大数据、数字经济紧
密融合, 实现了成渝城市群高质量发展。

(2) 发展示范型

西安。由于地方政府在基础设施建设、教育资源等 方面的大力投入，促使西安外包服务快速发展。同时陕 西自贸试验区抓住自贸试验区建设机遇, 也为西部地区 服务外包行业的发展起到了示范作用。

\section{(3) 后起勃发型}

呼和浩特、兰州、昆明、乌鲁木齐。尽管政府出 台了一系列的优惠政策，并加大对基础设施投入，但 
是因为这些城市的服务外包业发展历史较短，承接业 务多为中低端的业务, 因此竞争力优势不是很明显, 但综合实力上升相对较快。

\section{（4）进步潜力型}

贵阳、南宁、银川、拉萨、西宁。这五个城市中, 拉萨、银川、西宁整体的经济发展水平较低, 但是后期 可以承接更多的产业转移。贵阳和南宁近几年利用国家 政策、产业转移等机遇, 发展速度快, 进步空间相对较 大。

\section{4. 中国西部地区服务外包政策建议与启示}

本文通过因子分析和聚类分析, 把我国西部地区重 要的 12 个省会城市服务外包划分为四类: 核心引领型、 发展示范型、后起勃发型、进步潜力型。为避免城市之 间外包行业发展模式重复, 经济效率低下等情况, 作为 我国最具发展潜力的西部地区, 各个城市之间应该发挥 各自的优势, 走错位竞争、差异化发展的道路, 形成区 域品牌效益, 实现自身效益最大化。

\section{1. 培育外包品牌, 创新引领发展}

重庆和成都作为西部地区的核心引领型城市，应该 加大培育具有市场竞争力的市场主体以及具有影响力 与知名度的外包品牌, 同时也要依托西部地区金融商贸 中心的地位优势, 运用技术创新和服务创新推动金融外 包、服务外包的引领式发展。

\section{2. 提高集聚效应, 实现协同发展}

西安作为西部地区的发展示范型城市, 同时也作为 我国西部开放和 “一带一路” 的重要枢纽, 应该确立服 务外包差异化的道路, 提高资源利用率。同时加强培养 各类服务贸易人才, 积极发挥产业园、人力资源服务孵 化园等服务发展示范区的集聚效应。

\section{3. 拓展市场规模, 加强平台建设}

呼和浩特、兰州、昆明、乌鲁木齐作为西部地区的 后起勃发型城市，应该加大对外企投资的优惠力度，为 企业创造良好的商业环境。此外也要加强公共服务平台 的建设, 对知识产权、基础设施以及人才吸引等方面继 续加大投入，更好地打造服务外包贸易产业链。

\section{4. 利用区位优势，优化营商环境}

贵阳、南宁、银川、拉萨、西宁作为西部地区的 进步潜力型城市, 应该不断地强化与企业的互联互动 机制, 紧扣 “一带一路” 的发展定位。利用数字经济
增速、加快打造面向东盟的数字经济协同发展集聚区 等区位优势，促进服务外包产业向好发展。

\section{5. 结论}

本文以核心竞争力理论为依托，通过因子分析与聚 类分析的方法, 将中国西部地区核心城市划分为四类: 核心引领型、发展示范型、后期勃发型与进步潜力型。 并根据西部地区 12 大核心城市的服务外包行业特点, 给出相应的建议与措施: 重庆和成都应该培育外包品牌, 创新引领发展; 西安要提高集聚效应, 实现协同发展; 呼和浩特、兰州、昆明、乌鲁木齐应该积极拓展市场规 模, 加强平台建设; 贵阳、南宁、银川、拉萨、西宁可 以利用区位优势，优化营商环境。中国西部地区的服务 外包行业应该紧扣“一带一路”发展定位, 利用互联网、 大数据等新兴手段, 为经济发展增添活力。

\section{REFERENCES}

[1] Xu, M.Z.(2019)The exploration and practice of cultivating international software service outsourcing talents by means of Sino-foreign cooperation. Technology and Economic Guide.,27(16):165+164.

[2] Xi,J.P.(2019) Together, we will create a bright future for "one belt and one road". Practice in Foreign Economic Relations and Trade., (5):4-7.

[3] Gu,L. M.,Chen,Y.Q.(2019) Impact mechanism of "the Belt and Road" international service outsourcing on inclusive growth - a case study of zhejiang province. Journal of Commercial Economics., (2):122-125.

[4] Huang, H., Wu,S.M.(2019) Analysis on the current situation and countermeasures of International service outsourcing in China. Practice in Foreign Economic Relations and Trade., (12):86-89.

[5] Dai, J.,Yan,S.Q.(2018) Study on the Competitiveness of Jiangsu to Undertake "The Belt and Road" International Service Outsourcing-An Empirical Analysis Based on 19 Provinces' Service Outsourcing Data. Science \& Technology and Economy., 31(3):1-5. 